\title{
Short communication: Chronology of different sexual behaviors and motion activity during estrus in dairy cows
}

\author{
H. Dobson, ${ }^{1}$ J. Williams, J. E. Routly, D. N. Jones, J. Cameron, A. Holman-Coates, and R. F. Smith \\ Leahurst Campus, School of Veterinary Science, University of Liverpool, Neston, CH64 7TE, United Kingdom
}

\begin{abstract}
In studying the efficiency of a variety of methods for estrus detection in a large dairy herd, we suspected a definite sequence of estrus signs. Consequently, we observed a subset of animals continuously between 0400 and $2400 \mathrm{~h}$, making a note of the precise timing and frequency of each sexual behavior. Sixteen HolsteinFriesian cows, $>20 \mathrm{~d}$ postpartum, were equipped with motion activity-sensing neck collars and had milk progesterone profiles monitored simultaneously. The duration between the first and last observed estrus behavior was (mean $\pm \mathrm{SE}$ ) $14.0 \pm 1.9 \mathrm{~h}$, with a range 8.5 to $28.75 \mathrm{~h}$. The duration of standing to be mounted $(\mathrm{STBM})$ was $4.68 \pm 1.49 \mathrm{~h}$, with a range of 0.25 to $18.25 \mathrm{~h}$. Sniffing the vulva of another cow occurred on average $5.5 \pm 1.3 \mathrm{~h}$ (range $=0.25-18.25 \mathrm{~h}$ ) before the first STBM. By ranking the first appearance of each behavior, we established that sniffing was followed by the active behaviors of mounting another cow and not accepting a mount, as well as the passive behaviors of being sniffed and STBM by another cow. Chin resting occurred before not accepting a mount and STBM. All these behaviors were observed in the reverse order after the last STBM. The mean profile of motion activity revealed an increase in motion activity with the onset of exploratory behaviors, and highest values occurred within the period of STBM. Such distinct behavioral sequences may be controlled by changes in peripheral progesterone and estradiol concentrations, as well as by subtle independent mechanisms via pheromones in differing concentrations or divergent composition.
\end{abstract}

Key words: pheromones, sniffing, mounting, motion

\section{Short Communication}

To achieve successful reproduction, it is essential for sperm to fertilize the ovum at a precise time. Consequently, female sexual behavior begins shortly before

Received December 23, 2017.

Accepted April 1, 2018.

${ }^{1}$ Corresponding author: hdobson@liv.ac.uk the LH surge that triggers ovulation (Dobson, 1978; Morris et al., 2011). Several species within the family Bovidae also display estrus behaviors in all-female groups. This is thought to be part of a strategy engaged to attract males across large savanna grazing plains (Estes, 1966), although these attracting behaviors are also displayed in domesticated herds. In present-day intensive dairy herds, a need exists to enhance genetic improvement, for which AI is essential. Hence, farm staff need a clear understanding of the timing of all estrus behaviors to inseminate cows with a successful outcome.

In studying the efficiency of a variety of methods for estrus detection in a large dairy herd (Holman et al., 2011), we suspected a definite sequence of estrus signs could be determined. Consequently, during the latter part of that study, we watched a subset of animals continuously between 0400 and $2400 \mathrm{~h}$, making a careful note of the timing and frequency of each estrus event.

We performed this study under a UK Home Office license for work on living animals and with the approval of the University of Liverpool Ethical Review Process. As part of the large study, we monitored a whole herd of approximately 200 Holstein-Friesian cows that calved throughout the year on 1 commercial-housed UK dairy farm. Mean milk sales per cow were around 11,000 L annually, with average peak yields of $54 \mathrm{~L} / \mathrm{d}$. At any one time, a group of approximately 80 cows in their first to eleventh lactation were housed in a 100-cubicle shed with grooved concrete passageways that were automatically scraped clean every $2 \mathrm{~h}$. Within on-going herd management, every 2 to $3 \mathrm{~d}$ cows entered the shed $2 \mathrm{~d}$ after calving and left in rotation 4 mo later. Milking of all cows took place 3 times a day, starting at 0530 , 1400, and $2030 \mathrm{~h}$. All animals had continual access to a TMR that was pushed up to a feed-fence 5 times a day. All fertility examinations and treatments required during the study took place as part of the normal activity on the farm.

In the present subset study, every third week from May to August we recruited 4 to 6 cows before their second or third expected estrus, between 40 to $80 \mathrm{~d}$ postpartum. Each cow had a large unique number 
freeze-branded on its rump to aid identification. Cows were observed in 3-hour blocks by 2 research staff, who recorded the precise times and frequency of behavioral signs of estrus continuously between 0400 and $2400 \mathrm{~h}$, including the period when the cows were gathered for milking. The layout and lighting (200 lx for $18 \mathrm{~h} / \mathrm{d}$ with a 6 -h period of $20 \mathrm{~lx}$ ) permitted easy observation, with a freely accessible, open lit outdoor concreted loafing area $(20 \times 200 \mathrm{~m})$ being a congregating place for cows in estrus. Observations were conducted by walking among the cows while noting the signs such as vulva sniffing/vulva being sniffed, chin resting/being chin rested on, mounting others, not accepting a mount, and standing to be mounted (STBM). The herd had been acclimatized to the research staff by frequent visits for 3 mo before the study.

At the time of entry to the study, all cows were fitted with Heatime neck collars (SCR Engineers, Netanya, Israel), with data being downloaded to a dedicated program (Dataflow, SCR Engineers) in 2-h blocks at the milking parlor exit. According to the manufacturer's specification, a value of greater than 4.7 standard deviations above the mean of the previous eight 2-h blocks represented an increase. Data were collated at the end of the study for each cow to produce a motion profile relative to the time of STBM. Because motion activity data were downloaded in 2-h blocks, the value at the time of STBM was recorded as occurring in the middle of the prior 2 -h block (i.e., $1 \mathrm{~h}$ before, with all other data points calculated $2 \mathrm{~h}$ before or after).

Milk samples for progesterone analysis were collected each Tuesday and Friday throughout the study. All samples were taken immediately before milking and promptly stored at $-20^{\circ} \mathrm{C}$ without preservative. Progesterone was analyzed as pregnancy metabolites in 50 $\mu \mathrm{L}$ of whole milk samples using an established enzymeimmunoassay (Walker et al., 2008). For the present study, the minimum detectable amount was $0.02 \mathrm{ng} /$ $\mathrm{mL}$, and the intra- and interassay coefficients of variation were 9.7 and $15.8 \%$, respectively. When values were less than $0.2 \mathrm{ng} / \mathrm{mL}$, luteal tissue was considered to be absent, whereas values greater than $0.3 \mathrm{ng} / \mathrm{mL}$ indicated the presence of luteal tissue. Progesterone profiles were produced for each study animal to indicate potential estrus periods identified by the research staff or neck collars. The term "potential event" used in data analysis was defined as each time progesterone decreased below $0.2 \mathrm{ng} / \mathrm{mL}$, preceded and followed by at least 2 values above $0.3 \mathrm{ng} / \mathrm{mL}$.

Every $2 \mathrm{wk}$, the same member of the research team assessed each cow's BCS using a 1 to 5 system incorporating 0.5 scores (Edmonson et al., 1989), and lameness was assessed using a standardized 1 to 5 system (Sprecher et al., 1997). Treatments for lameness and mastitis followed normal farm practice, with regular or remedial foot trimming and antibiotic treatment for udder infections.

A total of 42 potential estrus periods in 33 cows were identified, out of which data from 14 potential estrus events were discarded because they had fewer than 10 observations of any estrus behavior (insufficient for statistical analysis): 9 silent periods were from 3 individual cows, and 5 from 5 different cows. In none of the 14 excluded periods were cows observed STBM, nor was an increase in activity recorded. Data from another 6 potential estrus events were discarded because evidence from activity monitors showed behaviors had started in the 4 -h period when visual observations were not made (0000 to $0400 \mathrm{~h}$ ). Six cows had more than 1 estrus period monitored; in each case, only data from the second estrus period were retained for analysis.

Data were analyzed using Minitab (Version 14, Minitab Inc., State College, PA). Results were expressed as mean $( \pm \mathrm{SE})$. Analysis of variance analyses with post hoc Tukey's comparisons were used to examine the frequency and timing of different sexual behaviors. Differences between first and last appearance ranks of behaviors were subjected to nonparametric analysis (Mann-Whitney). All differences were considered significant when $P<0.05$.

A total of 16 potential events ( 1 per cow) were analyzed, and these cows had a mean lameness score of $1.41 \pm 0.11$ and a mean BCS of $2.47 \pm 0.10$. For 14 out of 16 potential events, another cow was in estrus in the shed at the same time.

The frequency and range of each behavior is given in Table 1; each cow did not display every behavior. Sniffing the vulva of another cow, chin resting on the rear of another cow, and being chin rested upon by another cow were the most frequently observed behaviors with not accepting a mount being the least frequent (indeed, this latter behavior was not observed in 6 cows). These frequency data are similar to those previously noted

Table 1. Frequency ( \pm SE and range) of observed estrus behaviors

\begin{tabular}{|c|c|c|c|}
\hline \multirow[b]{2}{*}{ Behavior } & \multirow{2}{*}{$\begin{array}{l}\text { No. of } \\
\text { cows }\end{array}$} & \multicolumn{2}{|c|}{ Frequency } \\
\hline & & Mean \pm SE & Range \\
\hline Sniffing & 16 & $57.3 \pm 9.9^{\mathrm{a}}$ & $4-122$ \\
\hline Sniffed & 16 & $27.5 \pm 5.8^{\mathrm{bcd}}$ & $3-74$ \\
\hline Chin resting & 16 & $45.6 \pm 8.4^{\mathrm{ab}}$ & $3-102$ \\
\hline Chin rested & 14 & $39.8 \pm 9.7^{\mathrm{abc}}$ & $5-135$ \\
\hline Mounting & 14 & $12.6 \pm 2.5^{\mathrm{cd}}$ & $1-27$ \\
\hline Did not accept mount & 10 & $4.9 \pm 1.2^{\mathrm{d}}$ & $1-13$ \\
\hline Standing to be mounted & 13 & $9.69 \pm 3.0^{\mathrm{cd}}$ & $1-30$ \\
\hline
\end{tabular}

$\overline{{ }^{\mathrm{a}-\mathrm{d}} \text { Within a column, values with different superscript letters are differ- }}$ ent $\left(P<0.001 ; \mathrm{r}^{2}=29.4\right.$; ANOVA with post hoc Tukey test $)$. 
(Roelofs et al., 2005; Walker et al., 2008; Sveberg et al., 2011),

The duration between the first and last observed estrus behavior was $14.0 \pm 1.9 \mathrm{~h}$, with a range of 8.5 to $28.75 \mathrm{~h}$. The duration of STBM was $4.68 \pm 1.49 \mathrm{~h}$, with a range of 0.25 to $18.25 \mathrm{~h}$.

Using the time of the first STBM as a reference point (thus excluding data from 3 cows that did not STBM), the time from the first observation of each behavior to the first STBM was calculated. Similarly, the time from the last observation of each behavior after the last STBM was calculated. Figure 1 shows that all the exploratory behaviors started, on average, 4 t $5 \mathrm{~h}$ before STBM, but we found no differences in the timings before or after STBM or in the durations of individual sexual behaviors; this was likely because the ranges were large. The mean profile of motion activity (Figure 1) revealed an increase in motion activity with the onset of exploratory behaviors, and the highest values occurred within the period of STBM.

To overcome wide ranges in the sexual behavior data, a nonparametric approach was used to identify a sequence between onsets of each behavior. The time of the first or last observation of each behavior was ranked within a cow and the mean ranks for behaviors in all cows were compared (Figure 2). Sniffing was followed by being sniffed, mounting another cow, not accepting a mount, and STBM. Chin resting was followed by not accepting a mount and STBM (Figure 2; right columns). The last observation of each behavior was observed in the reverse order after the last STBM (Figure 2; left columns); the last STBM was followed by the last observation of being chin rested, chin resting, being sniffed, and sniffing.

We noted wide ranges in the data for both the frequencies and timings of different sexual behaviors during the estrus period in dairy cows, more so than in ewes running with rams (Fergani et al., 2012). In the present study, the large ranges in cows were not associated with lameness or BCS and may have been due to recording only female-female interactions, but also possibly due to the many interruptions in a dairy cow's daily time budget. For example, in the present study the cows were gathered for approximately $1 \mathrm{~h}$ into a different part of the shed 3 times per day for milking, and further disruption was caused by food being pushed-up to the feed barrier 5 times per day. Nevertheless, a marked sequence of different sexual behaviors was observed. This is the first description of the chronology of these behaviors in cattle, but it must be emphasized that this is a preliminary study on Holstein cows in confinement facilities on concrete in a temperate zone. This experiment should be repeated with a larger number of animals in other environments before being translated into other settings such as different countries, different breeds, nonlactating heifers, dirt corrals, or pasture.

Beach (1976) proposed a classification of female sexual behavior into 3 components: attractivity, proceptivity, and receptivity. Attractivity refers to the

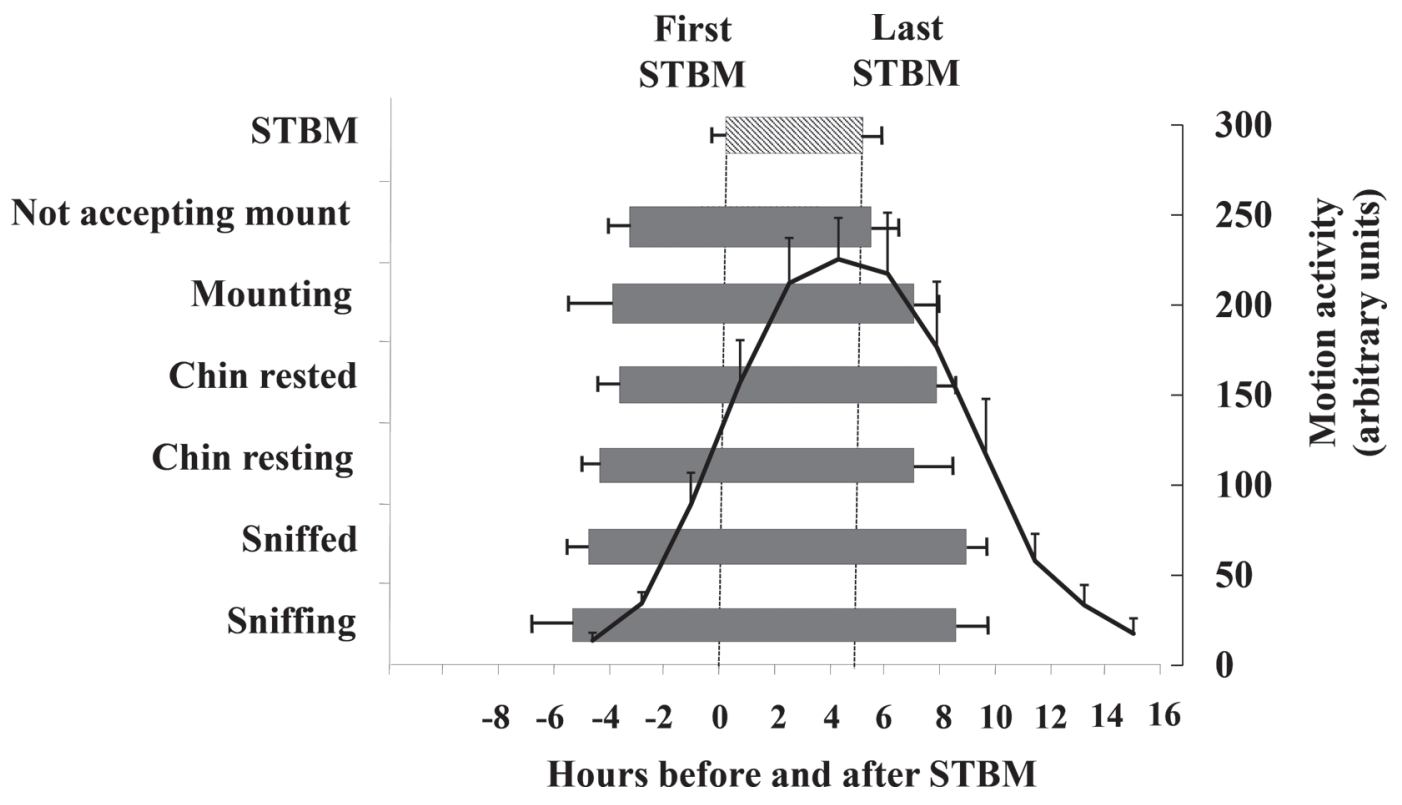

Figure 1. First and last appearance $( \pm \mathrm{SE})$ of each estrus behavior in 13 dairy cows in relation to the time of first and last standing to be mounted $(\mathrm{STBM})$ together with the contemporary mean $( \pm \mathrm{SE})$ of motion activity profile. Note: behavior data were recorded continuously, whereas motion activity data were downloaded every $2 \mathrm{~h}$. 


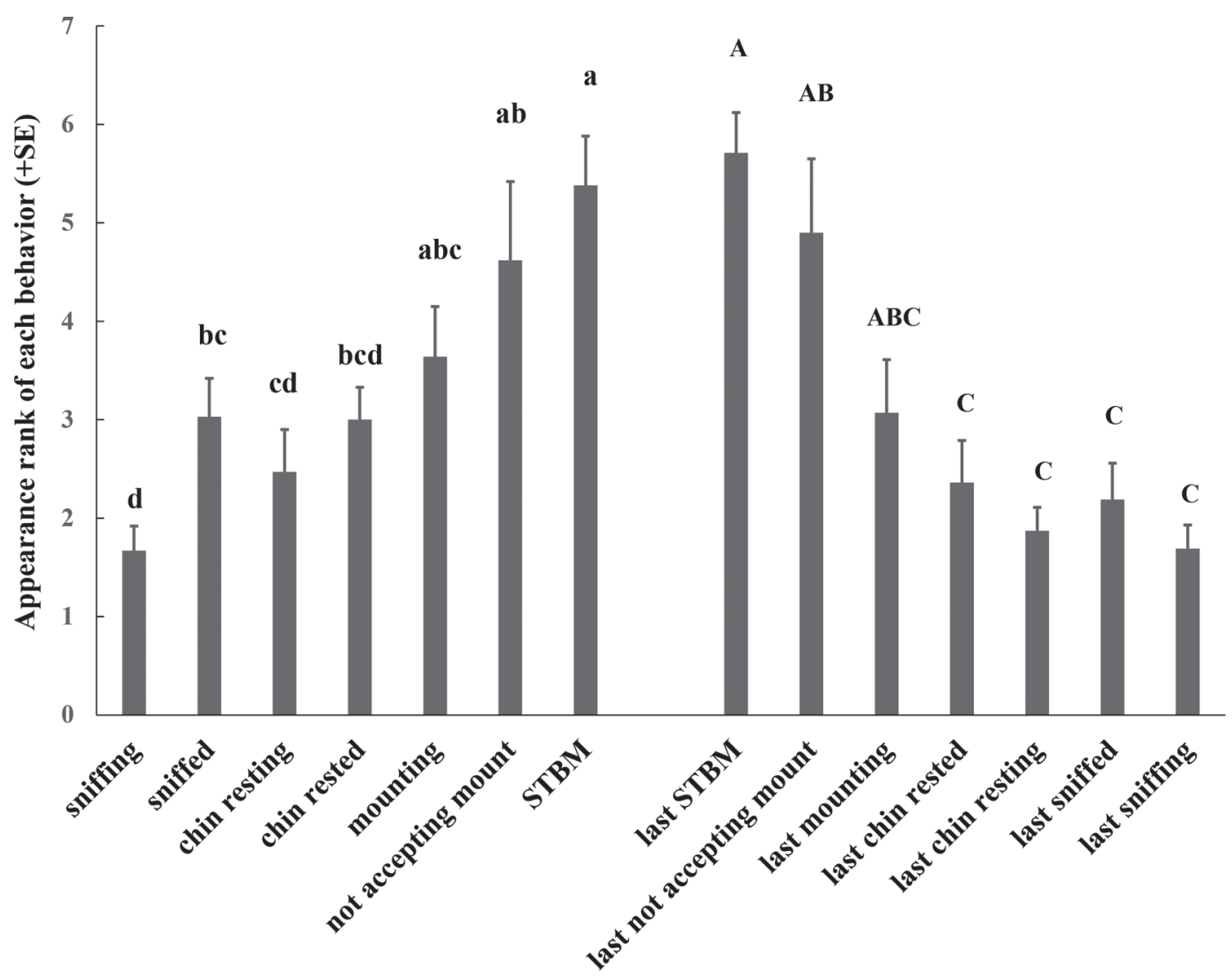

Figure 2. Mean $( \pm \mathrm{SE})$ rank of appearance and last appearance of each estrus behavior in 16 dairy cows. STBM = standing to be mounted. First appearance ranks (left columns) that do not share lowercase letters $(\mathrm{a}-\mathrm{d})$ were different $(P<0.05)$. Similarly, last appearance ranks (right columns) that do not share an uppercase letter $(\mathrm{A}-\mathrm{C})$ were different $(P<0.05)$.

female's value as a sexual stimulus and depends on stimuli passively emitted by females (pheromones) as well as on their own behavior. Whereas proceptivity consists of appetitive activities displayed by females (Fabre-Nys and Gelez, 2007). However, all sexual behaviors that are observed at the dairy farm level cannot be rigidly classified into the above categories. An increase in motor activity forms the basis of the neck collar estrus detection system and occurs around the time of the first sign of estrus (actively sniffing another cow). A mixture of passive and active behaviors follows, culminating in receptivity (i.e., STBM). Exploratory chin resting is probably a behavior among conspecifics to test whether it is the right time to expend energy in mounting the cow that is in estrus, with the endpoint being psychological reward for both individuals. Cows in estrus are agitated, vocalize, and often gather with other estrous or proestrous females into a sexually active group. Within this group, females display male-type courtship behavior and reciprocal mounting (Fabre-Nys and Gelez, 2007) and, indeed, the degree of estrus expression is markedly increased if several cows are in estrus at the same time (Helmer and Britt, 1985; Roelofs et al., 2005). Such mutual stimulation possibly occurs via pheromonal exchange.

From a mechanistic point of view, sexual behavior and the LH surge are controlled by the hypothalamicpituitary-gonadal axis. The fact that behaviors were displayed sequentially in a repertoire suggests that they may have common regulating factors (i.e., as concentrations of progesterone decrease at the end of the luteal phase and those of estradiol increase in the late follicular phase; Morris et al., 2011; Fergani et al., 2014). Equally, these behaviors may also be controlled by subtle independent mechanisms via pheromones in differing concentrations or divergent composition. In many species, these compounds serve as sexual attractants, promote sexual arousal and mating behavior, as well as modify neuroendocrinological aspects of reproduction (Johnston and Bronson, 1982; Okamura et al., 2010). However, their precise role in exhibition of sexual behaviors remains to be elucidated if progress is to be made in successful exploitation of new techniques in reproductive or behavior management. 


\section{ACKNOWLEDGMENTS}

All the authors are grateful to the farm staff for their help during all hours of the day and night. This research did not receive any specific grant from funding agencies in the public, commercial, or not-for-profit sectors. We also thank the reviewers for their suggestions that considerably improved the manuscript.

\section{REFERENCES}

Beach, F. A. 1976. Sexual attractivity, proceptivity and receptivity. Horm. Behav. 7:105-138.

Dobson, H. 1978. Plasma gonadotrophins and oestradiol during oestrus in the cow. J. Reprod. Fertil. 52:51-53.

Edmonson, A. J., I. J. Lean, L. D. Weaver, T. Farver, and G. Webster. 1989. A body condition scoring chart for Holstein dairy cows. J. Dairy Sci. 72:68-78.

Estes, R. D. 1966. Behaviour and life history of wildebeest (Connochaetes Taurinus Burchell). Nature 212:999-1000.

Fabre-Nys, C., and H. Gelez. 2007. Sexual behavior in ewes and other domestic ruminants. Horm. Behav. 52:18-25.

Fergani, C., J. E. Routly, D. N. Jones, L. C. Pickavance, R. F. Smith, and H. Dobson. 2014. Activation of cells containing estrogen receptor alpha or somatostatin in the medial preoptic area, arcuate nucleus, and ventromedial nucleus of intact ewes during the follicular phase, and alteration after lipopolysaccharide. Biol. Reprod. 91:141.

Fergani, C., A. K. Saifullizam, J. E. Routly, R. F. Smith, and H. Dobson. 2012. Estrous behavior, luteinizing hormone and estradiol profiles of intact ewes treated with insulin or endotoxin. Physiol. Behav. 105:757-765.

Helmer, S. D., and J. H. Britt. 1985. Mounting behavior as affected by stage of estrus cycle in Holstein heifers. J. Dairy Sci. 68:1290-1296.

Holman, A., J. Thompson, J. E. Routly, J. Cameron, D. N. Jones, D. Grove-White, R. F. Smith, and H. Dobson. 2011. Comparison of oestrus detection methods in dairy cattle. Vet. Rec. 169:47-54.

Johnston, R. E., and F. Bronson. 1982. Endocrine control of female mouse odors that elicit luteinizing hormone surges and attraction in males. Biol. Reprod. 27:1174-1180.

Morris, M. J., K. Kaneko, S. L. Walker, D. N. Jones, J. E. Routly, R. F. Smith, and H. Dobson. 2011. Influence of lameness on follicular growth, ovulation, reproductive hormone concentrations and oestrus behaviour in dairy cows. Theriogenology 76:658-668.

Okamura, H., K. Murata, K. Sakamoto, Y. Wakabayashi, S. Ohkura, Y. Takeuchi, and Y. Mori. 2010. Male effect pheromone tickles the gonadotrophin-releasing hormone pulse generator. J. Neuroendocrinol. 22:825-832.

Roelofs, J. B., F. J. van Eerdenburg, N. M. Soede, and B. Kemp. 2005. Various behavioral signs of estrous and their relationship with time of ovulation in dairy cattle. Theriogenology 63:1366-1377.

Sprecher, D. J., D. E. Hostetler, and J. B. Kaneene. 1997. A lameness scoring system that uses posture and gait to predict dairy cattle reproductive performance. Theriogenology 47:1179-1187.

Sveberg, G., O. Refsdal, H. W. Erhard, E. Kommisrud, M. Aldrin, I. F. Tvete, F. Buckley, A. Waldmann, and E. Ropstad. 2011. Behavior of lactating Holstein-Friesian cows during spontaneous cycles of estrus. J. Dairy Sci. 94:1289-1301.

Walker, S. L., R. F. Smith, D. N. Jones, J. E. Routly, and H. Dobson. 2008. Chronic stress, hormone profiles and estrus intensity in dairy cattle. Horm. Behav. 53:493-501. 